Res., Soc. Dev. 2019; 8(5):e3385970

ISSN 2525-3409 | DOI: http://dx.doi.org/10.33448/rsd-v8i5.970

\title{
Segmentação de mercado: o perfil do consumidor gay masculino
}

\section{Market segmentation: the gay consumer profile}

Segmentación de mercado: el perfil del consumidor gay masculino

Sidney Pereira da Silva

ORCID: https://orcid.org/0000-0001-6682-8773

Universidade de São Paulo, Brasil

E-mail: sidneypsilva@live.com

Caio Flávio Stettiner

ORCID: https://orcid.org/0000-0002-4479-7416

Centro Universitário Campo Limpo Paulista, Brasil

E-mail: cstettiner@gmail.com

Roberto Padilha Moia

Universidade São Caetano do Sul, Brasil

ORCID: http://orcid.or/0000-0002-7204-0162

E-mail: robertopadilha@uoil.com.br

Alex Paubel Junger

ORCID: https://orcid.org/0000-0002-5072-1012

Faculdade de Tecnologia Termomecânica, Brasil

E-mail: alexpaubel@hotmail.com

Recebido: 09/02/2019 | Revisado: 27/02/2019 | Aceito: 06/03/2019 | Publicado: 06/03/2019

\section{Resumo}

$\mathrm{O}$ artigo buscou identificar e analisar de que forma o consumidor gay se comporta, quais são os hábitos de consumo e como eles avaliam a comunicação direcionada para o segmento. Para desenvolvimento do artigo foi aplicado um questionário, com 43 perguntas, por meio de plataforma online com foco em três eixos: $1^{\circ}$ dados demográficos; $2^{\circ}$ dados sobre hábitos de consumo e $3^{\circ}$ dados sobre as motivações e influencias antes e depois da compra de produtos. Os resultados da pesquisa demonstraram uma tendência na qual a maioria dos entrevistados da amostra possuem ensino superior e aproximadamente um quarto (19,52\%) tem união estável. Eles percebem quando as marcas estão apenas atrás do dinheiro do segmento. Nenhum dos entrevistados levantou bandeira para que as campanhas de marketing sejam obrigadas a incluir gays ou para tratá-los diferentes dos outros consumidores, mas indicam 
que a forma natural e inclusiva, sem diferenciá-los dos heterossexuais, é o caminho para as equipes de marketing trabalharem.

Palavras-chave: marketing; mercado gay; influencias; sexualidade; consumo.

\begin{abstract}
This article aims to identify consumer behavior within the gay market segment, analyze the underlying consumption habits, and understand consumer sentiment about the corporate messages directed to this market segment. Supporting this research was an online questionnaire of 43 questions relating to consumer focusing on three axes: 1) demographics, 2) consumption habits, and 3) motivations and influences before and after the purchase of products. The majority of respondents were highly educated, and almost a fifth (19.52\%) of them were in a stable relationship. All respondents reacted negatively to perceived brand attempts to target "pink money". With respect to marketing campaigns, no respondents felt that companies were obliged to include or treat the gay community differently. In fact, they indicate that marketers should develop natural, inclusive messaging campaigns that avoid differentiating the gay consumer segment from their heterosexual peers.
\end{abstract}

Keywords: marketing; gay market; influences; sexuality; consumption.

\title{
Resumen
}

El artículo buscó identificar y analizar de qué forma el consumidor gay se comporta, cuáles son los hábitos de consumo y cómo ellos evalúan la comunicación dirigida al segmento. Para el desarrollo del artículo se aplicó un cuestionario, con 43 preguntas, a través de plataforma online con foco en tres ejes: 1o datos demográficos; $2^{\circ}$ datos sobre hábitos de consumo y $3^{\circ}$ datos sobre las motivaciones e influencias antes y después de la compra de productos. Los resultados de la investigación mostraron una tendencia en la que la mayoría de los encuestados de la muestra poseen enseñanza superior y aproximadamente una cuarta $(19,52 \%)$ tiene una unión estable. Se dan cuenta de que las marcas sólo están detrás del dinero del segmento. Ninguno de los encuestados ha levantado bandera para que las campañas de marketing estén obligadas a incluir gays o para tratarlos diferentes de los demás consumidores, pero indican que la forma natural e inclusiva, sin diferenciarlos de los heterosexuales, es el camino para los equipos de marketing trabajar en.

Palabras clave: comercialización; mercado gay; influencias; la sexualidad; el consumo. 


\section{Introdução}

Para a sociedade em geral, homossexuais, travestis e transexuais são vistos como sendo a mesma coisa, mas não são. Segundo Reinaudo e Bacellar (2008), a enorme maioria dos gays não querem alterar seu corpo ou se vestir com roupas do sexo oposto. Autores como Combs e Witeck (2006), e Reinaudo e Bacellar (2008) ao avaliarem o mercado concordam que mesmo com o espaço já conquistado, os gays ainda são vistos e conhecidos muito mais pelos estereótipos do que pela diversidade existente no segmento. Esses estereótipos são baseados na ignorância e difundidos por meios de comunicação oportunistas, que buscam alvos fáceis de audiência (Souza, 2007). Para alcançar esse público é necessário compreender a diversidade existente e não ficar apoiado somente nos clichês e estereótipos.

Como vivemos em uma economia com abundância de ofertas de produtos e serviços, porém com escassez de clientes, é necessário estudar o comportamento e entender as necessidades especificas dos clientes em seus nichos para o sucesso de qualquer empreendimento (Kotler e Kotler, 2013).

Os Estados Unidos, por exemplo, foram os primeiros a identificar o chamado "pink money" e a estudar o segmento, tendo já alguns livros e pesquisas organizados sobre o consumidor LGBTI. No Brasil já é possível ter uma pequena visualização do potencial desse mercado, mas que permanece sendo mal explorado devido a falta de entendimento sobre esse consumidor. Segundo relatório da OUT NOW, liberado em 2017, o Brasil tem uma das mais dinâmicas e maiores comunidades LGBTI do mundo, estimado em 9.5 milhões em idade adulta. Portanto dar atenção ao segmento gay pode trazer bons resultados para as empresas.

Para muitos estudiosos o movimento pelos direitos LGBTI começou a se organizar em 1969 nos Estados Unidos. O fato, que virou documentário, aconteceu em um bar chamado "Stonewall Inn" (Venturi e Bokany, 2011). O confronto entre policiais e os frequentadores gays foi reportado mundo afora e virou um símbolo de resistência e busca por direitos iguais (Reinaudo e Bacellar, 2008). Após esse fato empresários começaram a pesquisar e desenvolver produtos direcionados para esse segmento no mercado norte-americano.

Podemos dizer que no Brasil o mercado gay começou a tomar forma em 1990, quando a Organização Mundial da Saúde [OMS] aprovou a retirada a palavra 'homossexualismo' da Classificação Internacional de Doenças e a sigla GLS (Gays, Lésbicas e Simpatizantes) passa a ser usada para identificar alguns locais frequentados por gays. Em 1993 surge o festival Mix Brasil da Diversidade Sexual; em 1994 o primeiro site GLS brasileiro na internet intitulado 
Mundo Mix; em 1995 a fundação da Associação Brasileira de Gay, Lésbicas e Transexuais [ABGLT]; em 1997 a Parada LGBT; em 1999 a criação do Fórum Paulista de Gays, Lésbicas, Bissexuais e Transgêneros. Dois fatos importantes que antecedem o período de estruturação do mercado foram: a criação do Núcleo de Ação pelos Direitos dos Homossexuais, posteriormente Grupo Somos de Afirmação Homossexual, em maio de 1978 em São Paulo (Zanatta, 1997); e na área dos impressos a criação do primeiro jornal dirigido ao público gay, publicado entre 1978 e 1981, o Lampião da Esquina, que pode ser tomado como um divisor de águas e o início do amadurecimento político do movimento (Green e Polito, 2004). Esses primeiros passos sempre estiveram mais ligados à busca por direitos e visibilidade do movimento LGBTI e menos ao potencial de mercado.

Aos poucos os gays foram conseguindo conquistar seus direitos e deixando de viver nos guetos. O reconhecimento da união estável de pessoas do mesmo sexo em diversos países como: Suécia, Holanda, Bélgica, e o Brasil, cujo o Supremo Tribunal Federal a reconheceu por unanimidade em maio de 2011, impulsionou o mercado e os setores de consumo, que passam a focar e produzir produtos e serviços para o público gay em busca do chamado "pink money” (Reinaudo e Bacellar, 2008), porém sem muitos dados sobre os hábitos desse consumidor.

Durante esses anos as equipes de marketing vem tentando dialogar com esse nicho. Em 1994, a Folha de São Paulo, por exemplo, colocou uma campanha publicitária na televisão aberta na qual um moço chegava em casa e apresentava o namorado aos pais. Pode se dizer que foi o primeiro anúncio brasileiro a retratar a relação homoafetiva de forma natural (Reinaudo e Bacellar, 2008). Outro exemplo de inclusão e respeito à diversidade foi a campanha da pomada Nebacetin, na qual aparecem várias famílias e entre elas um casal formado por dois homens de mãos dadas, carregando um bebê no colo (Ribeiro, 2010). Campanhas como essas demonstram que algumas empresas vem tentando conquistar esse consumidor.

Em 2010 o censo divulgou que o Brasil tem mais de 60 mil casais homossexuais vivendo juntos. Esses casais são identificados pelo mercado norte-americano como "DINKs", termo de origem inglesa que significa "Double Income, No Kids" - dupla renda sem filhos termo esse usado para comparar o poder de consumo dos homossexuais em relação aos heterossexuais que, em geral, devido principalmente aos filhos possuem outras prioridades e 
acabam não investido tanto em lazer, cultura e turismo como os gays (Reinaudo e Bacellar, 2008).

Outro dado importante é a quantidade de turistas e os valores que são gerados em eventos especiais. Segundo dados oficiais levantados pelo site São Paulo Turismo, a Parada Gay na capital paulista movimentou em 2010 mais de $\mathrm{R} \$ 188$ milhões, perdendo apenas para o Grande Prêmio Brasil de Fórmula 1 com R \$ 238 milhões. O mesmo levantamento mostra a quantidade de turistas que os grandes eventos trouxeram para a cidade, e a Parada Gay ficou em primeiro lugar com 403 mil, seguido pela Virada Cultural com 328 mil e a Bienal do Livro com 290 mil turistas. Com essas informações é possível perceber que o segmento também movimenta a economia da cidade.

Kotler et al. (2017) diz que na era do marketing 4.0 as marcas estão deixando de ser exclusivas para ser inclusivas, o que não significa ser semelhante, mas sim viver em harmonia mesmo com as diferenças existentes. Podemos observar isso quando analisamos como empresas e empresários americanos estão desenvolvendo produtos e serviços direcionados a esse público. O Netflix, por exemplo, tem com frequência em suas series originais personagens gays e, até mesmo a Disney, tem um personagem gay na série Andi Mack lançada em 2017 com foco no público juvenil. No mesmo ritmo algumas novelas brasileiras de rede aberta já começaram a tratar os gays como personagens em seus enredos e não somente usá-los de forma caricata para atrair audiência. Ações como essas demonstram que a visibilidade do segmento está ficando mais forte .

Para Junger (2017), as mudanças sociais e políticas pelas quais os países passam são fatores que influenciam o mercado. Para Sender (2004), os preconceituosos podem não gostar dos gays, mas não conseguirão ignorá-los por muito tempo como consumidores com poder de compra significativo já que toda atividade econômica causa mudanças políticas e vice-versa.

Nesse sentido objetiva-se com esse estudo identificar e analisar de que forma esse potencial consumidor se comporta, quais são os hábitos de consumo e como eles avaliam a comunicação direcionada para o segmento, já que o mercado ainda é carente de estudos e publicações com dados sobre o segmento gay que possam ajudar as equipes de marketing a entender que nicho é esse e como se aproximar dele. Em termos gerais, de 1990 até 2018, o mercado de consumo gay vem demonstrando crescimento e se for bem trabalhado tem um potencial significativo para a economia das empresas. 


\section{Material e Métodos}

Este estudo é do tipo exploratório, pois busca entender o comportamento dos consumidores gay masculino e estabelecer bases que levem a estudos futuros (Sordi, 2017). Por se tratar de um estudo de segmentação, definiu-se como sendo objeto de pesquisa apenas o grupo que se identifica como homossexual masculino, já que o segmento LGBTI contém uma diversidade muito ampla de micronichos ou microgrupos como identificou Kotler e Kotler (2013).

Para desenvolvimento do artigo foi aplicado um questionário com 43 perguntas por meio de plataforma online durante o mês de agosto de 2018 e disponibilizado em redes sociais para participação de forma voluntária do público. Os 210 participantes tiveram acesso ao mesmo questionário, não houve variação com relação a ordem e ou redação das perguntas. A delimitação da localidade dos participantes não foi levada em consideração no estudo, sendo aberto para participantes de diversos estados do Brasil.

As questões foram desenvolvidas com o interesse em entender o perfil do consumidor, os fatores levados em consideração no momento da compra, além de buscar identificar de que forma as empresas deveriam se aproximar desse nicho. As perguntas foram divididas em três eixos: $1^{\circ}$ dados demográficos como idade, estado civil e escolaridade; $2^{\circ}$ dados sobre hábitos de consumo como frequência, interesse por bens duráveis e gastos com viagens e compras; $3^{\circ}$ dados sobre as motivações e influencias antes e depois da compra de produtos.

Optou-se por um questionário ampliado porque apenas dados demográficos são insuficientes para prever o comportamento de um grupo de consumidores. Portanto perfilar um nicho de mercado demanda também a coleta informações sobre estilo de vida e dados psicográficos (Rosenwald, 2005).

\section{Resultados e Discussão}

Para transformar clientes em consumidores leais e advogados de uma marca/produto, é necessário segmentar e trabalhar a comunicação direcionada para os nichos escolhidos. E, para se ter uma comunicação eficiente que gere os resultados esperados, é necessário realizar estudos sobre perfil comportamental desses clientes e traçar estratégias especificas focadas no público alvo. Segundo Roth (2016), os mercados conectam compradores e vendedores através do "matching process", o qual ajuda a satisfazer os desejos e necessidades dos consumidores. 
Para Kotler e Keller (2012) ao tentar suprir as necessidades dos consumidores e gerar lucro as empresas precisam conhecer os fatores sociais e culturais que podem interferir no processo de aproximação, além de estudar os grupos de referências no qual eles podem estar inseridos.

$\mathrm{Na}$ mesma linha de pensamento analítico sobre mercado e clientes encontramos Yanaze (2011), que observa que devemos entender as características do comportamento que podem influenciar em cada etapa do ciclo do consumo. Esse entendimento é fundamental para definir a estratégia de produto, a distribuição, o preço e a comunicação, e assim criar um plano de marketing eficaz que gere retorno para a empresa. Para ele o consumo é parte essencial para o sucesso do marketing, assim como conhecer bem o consumidor é essencial para efetivação do consumo. Assim como é parte das responsabilidades das equipes de marketing definir o mercado-alvo, captar e fidelizar clientes por meio da criação de valores ao suprir as necessidades e desejos dos consumidores.

Constatou-se que a menor representatividade de respondentes por faixa etária foram: acima de 60 anos com apenas $0,95 \%$ de participantes na pesquisa, e o grupo com idade entre 18 e 20 anos com 4,76\%. Os outros grupos tiveram uma representação significativa sendo que: $29,05 \%$ tem entre 21 e 29 anos, $35,71 \%$ situavam-se na faixa entre 30 e 39 anos, 19,52\% entre 40 e 49 anos, e 10,00\% entre 50 e 59 anos. A faixa etária com maior representatividade no estudo, situou-se entre 21 e 39 anos de idade, representando a soma de 64,76\% da amostra.

Quanto a escolaridade: $12,86 \%$ tem ensino médio completo, 50,00\% ensino superior, 27,62\% pós-graduação, 6,67\% mestrado e 2,86\% doutorado. Notou-se com estes dados, que houve uma tendência que os respondentes que participaram da pesquisas sobre o segmento possuem nível superior e pós graduação, totalizando 77,62\% do total de participantes.

O grau de escolaridade se reflete na forma com que os entrevistados se projetam socialmente e no grau de aceitação da sexualidade com relação a sociedade. Foi possível observar que $70,48 \%$ dos entrevistados assume a sexualidade para qualquer pessoa que perguntar e apenas 2,86\% não se assumiu para ninguém, porém mesmo não sendo gays abertamente para a sociedade, eles participam de comunidades nas redes sociais e se mantém conectados com outros gays, tornando-se então um tipo de consumidor que as campanhas de marketing online podem alcançar. O restante da amostra se assume para o núcleo mais intimo como família, amigos próximos e colegas de trabalho. Isso demonstrou que a aceitação da sexualidade já não é um tabu entre os participantes do estudo. 
O último grupo de questões para levantamento do perfil dos entrevistados, se focou no núcleo familiar, estado civil e renda. Detectou-se que mais da metade, totalizando $58,10 \%$ está solteiro, 20,00\% está namorando, 19,52\% tem união estável ou está casado, 1,43\% é divorciado e $1,43 \%$ viúvo. Com relação a núcleo com quem mora: $27,14 \%$ vive sozinho, $25,71 \%$ com o parceiro, $37,62 \%$ ainda vive com a família e 9,52\% com amigos. Sendo que do total da amostra $76,19 \%$ não tem filhos, $9,52 \%$ tem filhos e $14,29 \%$ não tem filho, mas pensa em adotar.

Na pergunta sobre renda, o estudo tentou identificar o poder de compra individual e também a soma total dos rendimentos dos casais que vivem juntos, para poder entender se no Brasil, assim como nos EUA, existem os chamados "DINKs - double income no kids", já que a soma das rendas representa um poder de compra maior quando não se tem filhos (Combs e Witeck, 2006). A faixa de renda que se destacou na pesquisa foi a que ganha acima de $\mathrm{R} \$ 6.678$ com 22,86\%, a dos que se situam entre $\mathrm{R} \$ 955$ a $\mathrm{R} \$ 1.908$ com $19,05 \%$ de representatividade, seguida das faixas entre $\mathrm{R} \$ 1.909$ e $\mathrm{R} \$ 2.862$ com $14,76 \%$ e com $13,33 \%$ os com rendimentos $\mathrm{R} \$ 2.863$ e $\mathrm{R} \$ 3.816$ conforme demonstrado na Tabela 1.

Tabela 1. Renda individual

\begin{tabular}{ll}
\hline Renda & Representatividade em \% \\
\hline Até $\mathrm{R} \$ 954$ & 3,81 \\
De $\mathrm{R} \$ 955$ a $\mathrm{R} \$ 1.908$ & 19,05 \\
De $\mathrm{R} \$ 1.909$ a $\mathrm{R} \$ 2.862$ & 14,76 \\
De $\mathrm{R} \$ 2.863$ a $\mathrm{R} \$ 3.816$ & 13,33 \\
De $\mathrm{R} \$ 3.817$ a $\mathrm{R} \$ 4.770$ & 10,00 \\
De $\mathrm{R} \$ 4.771$ a $\mathrm{R} \$ 5.724$ & 10,48 \\
De $\mathrm{R} \$ 5.724$ a $\mathrm{R} \$ 6.678$ & 5,71 \\
acima de $\mathrm{R} \$ 6.678$ & 22,86 \\
\hline Total & 100 \\
\hline
\end{tabular}

Fonte: Resultados originais da pesquisa 
$\mathrm{Na}$ soma total dos rendimentos do casal as faixas de renda que se destacam na pesquisa foram: $38,89 \%$ dos entrevistados possui renda conjunta acima de $\mathrm{R} \$ 10.000,18,52 \%$ estão no grupo com rendimentos entre $\mathrm{R} \$ 8.001$ a $\mathrm{R} \$ 10.000$ e com $20,37 \%$ os que se enquadraram na faixa de $\mathrm{R} \$ 4.001$ a $\mathrm{R} \$ 6.000$ conforme demonstrado na Tabela 2.

Tabela 2. Renda dupla dos que moram com o parceiro

\begin{tabular}{ll}
\hline Renda & Representatividade em \% \\
\hline Até $\mathrm{R} \$ 2.000$ & 1,85 \\
De $\mathrm{R} \$ 2.001$ a $\mathrm{R} \$ 4.000$ & 11,11 \\
De $\mathrm{R} \$ 4.001$ a $\mathrm{R} \$ 6.000$ & 20,37 \\
De $\mathrm{R} \$ 6.001$ a $\mathrm{R} \$ 8.000$ & 9,26 \\
De $\mathrm{R} \$ 8.001$ a $\mathrm{R} \$ 10.000$ & 18,52 \\
Acima de $\mathrm{R} \$ 10.000$ & 38,89 \\
\hline Total & 100 \\
\hline
\end{tabular}

Fonte: Resultados originais da pesquisa

Vale lembrar que a porcentagem da Tabela 2 se refere apenas a contagem dos que responderam viver com o parceiro $(25,71 \%$ da amostra total). Nesse grupo também foi possível analisar, comparando com as respostas sobre filhos, que $15 \%$ tem pelo menos um filho, $15 \%$ pensa em adotar e $70 \%$ não tem filho. Esses dados demonstram que os "DINKs" ainda são maioria no Brasil, porém identificou-se um micronicho que tem ou deseja ter filhos, sendo assim as equipes de marketing podem trabalhar com esse potencial de mercado e não perder a oportunidade de crescimento por estarem focadas apenas em mercados amplos como descreve Kotler e Kotler (2013) em Marketing de Crescimento.

Pode se inferir dos dados que a faixa etária entre 21 e 39 anos - que normalmente estão focados no processo de independência financeira, formação educacional e desenvolvimento de carreira - tendem a ser mais participativos em pesquisas ligadas ao segmento LGBTI. O nível de formação educacional também se reflete nos salários que os participantes da pesquisa recebem, bem como a forma com que eles lidam com aceitação da sexualidade. 
Procurou-se identificar o interesse por bens duráveis, frequência e volume de compras, uso de internet e tecnologia, o consumo de cultura e lazer. Para isso foram usadas 18 perguntas fechadas para possibilitar o agrupamento da amostra e assim entender as necessidades especificas do nicho pesquisado.

Quanto ao uso de tecnologia: 10,00\% tinha feito compra online nas últimas 24 horas, 28,57\% na última semana, 34,76\% no último mês, 17,62\% nos últimos 6 meses, ou seja, $90,95 \%$ da amostra fez pelo menos uma compra pela internet nos últimos 180 dias. Ao passo que 3,81\% fez no último ano, 3,33\% há mais de um ano e 1,90\% nunca comprou pela internet. Observando a porcentagem dos que usaram recentemente a internet para fazer algum tipo de compra, podemos perceber que os gays são "early adopters" no mercado de tecnologia, ou seja, adotam a tecnologia como parte do dia-dia (Reinaudo e Bacellar, 2008; Sender, 2004; Combs e Witeck, 2006). Dentro da mesma ideia dos "early adopters" verificamos o uso do smartphone para efetuar compras e constatou-se que 6,67\% já efetuou pelo menos uma compra via celular, 27,62\% entre duas a dez vezes, e 45,24\% mais de dez vezes. Como contraponto tivemos $18,10 \%$ dos participantes que nunca usou o celular para efetuar compras e 2,38\% não possui smartphone.

Sobre a preferência entre comprar na loja física ou via sistemas online, apenas 7,62\% disseram que preferem comprar apenas online, 8,57\% somente em lojas físicas e 83,81\% escolhe o local da compra com base no tipo de produto, preço e entrega. Isso demonstra uma sensibilidade com relação ao preço e a confiabilidade na hora de escolher determinados produtos online. Para atrair os grupos que não usam o smartphone durante as compras e os que preferem comprar em lojas físicas é necessário que as equipes de "UX - User Experience" ajudem a desenvolver aplicativos/sistemas que deem segurança aos usuários e facilitem o processo de compra.

Outros fatores analisados na pesquisa foram: a quantidade de horas que eles usam a internet, acesso a redes sociais, aplicativos de relacionamento e os meios de comunicação mais consumidos.

Verificou-se também que apenas $0,48 \%$ usam por menos de $1 \mathrm{~h}$ a internet diariamente, $5,71 \%$ até $2 \mathrm{~h}, 6,67 \%$ até $3 \mathrm{~h}, 13,33 \%$ até $4 \mathrm{~h}, 12,86 \%$ até $5 \mathrm{~h}$ e a maior parte dos entrevistados usam a internet mais de 6 h por dia, representando $60,95 \%$. 
Para entender o que eles mais fazem online, foi perguntado sobre quais são as redes sociais que acessam com frequência. Nessa pergunta era possível escolher mais de uma alternativa. Nenhuma das opções de respostas chegou a 100\%, porém pode-se constatar que os líderes na preferência de uso são: Instagram com 84,76\%, Facebook com 84,29\% e Youtube com 81,43\%. Seguidos por LinkedIn com 32,38\%, aplicativos de relacionamento com 30,95\%, Twitter com 24,76\%, Google+ com 20,95\% e Pinterest com 17,62\%. Com menos porcentagem de escolha apareceu Snapchat com apenas 6,19\% e a opção outras redes com $1,90 \%$. Somente $0,95 \%$ dos respondentes disseram que não usam nenhuma rede social com frequência conforme representado na Figura 1.

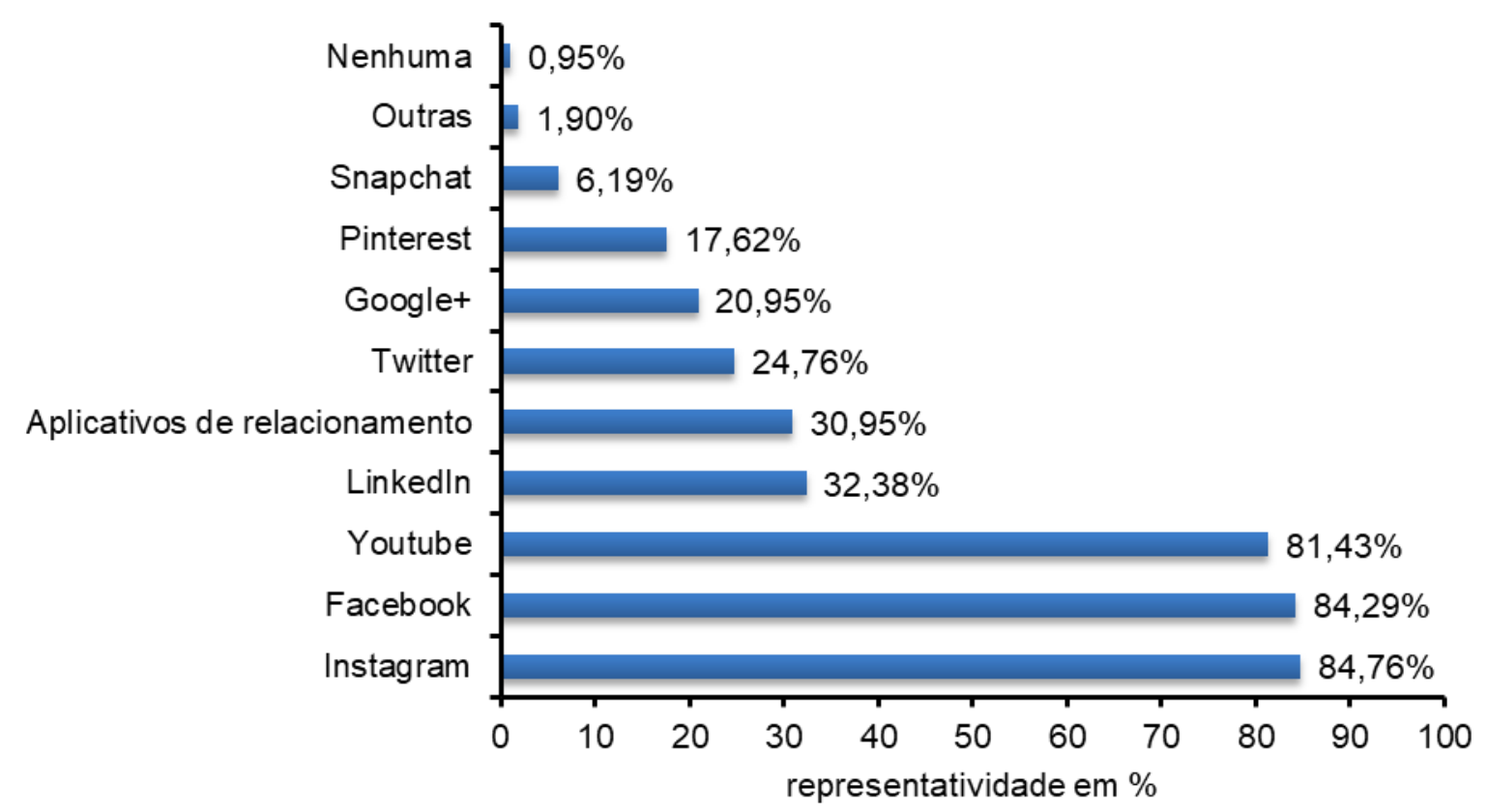

Figura 1. Redes sociais que os entrevistados acessam com frequência

Fonte: Resultados originais da pesquisa

Esses são dados extremamente relevantes para desenvolvimento de campanhas focadas nesse grupo, já que as mídias sociais são de baixo custo e serão o futuro das comunicações de marketing (Kotler et al., 2010). Os meios de comunicação mais consumidos foram: $65,71 \%$ jornais e/ou revistas online, $65,24 \%$ TV a cabo, 48,10\% TV aberta, 42,86\% rádio, 23,33\% jornais, $19,52 \%$ revistas e 4,29\% não usa nenhuma das alternativas com frequência. Comparando os dados de uso de internet com os meios de comunicação 
tradicionais foi possível verificar que o universo online tem se tornado a principal ferramenta de interação e consumo de informação nesse nicho. Isso acontece porque nas redes todos podem ser produtores de conteúdo e influenciadores em algum grau, o que possibilita uma interação maior entre usuários na qual a internet é a base utilizada para se obter uma experiência e promover a conectividade social (Kotler et al., 2017), ao passo que nos meios de comunicação tradicionais os espectadores são mais passivos. Não se deve ignorar o potencial da conectividade, que segundo Kotler et al. (2017), é adotada primeiramente pelos jovens, que são nativos digitais, mas na medida que a população envelhece, eles passarão a ser a maioria conectada a internet. A conectividade é tão importante que transcende as barreiras demográficas e esta mudando a forma com que o mercado e o marketing funcionam hoje.

Para identificar as mudanças no mercado perguntamos sobre o consumo com relação ao serviço de streaming que vêm substituído a venda de meios físicos de CDs e DVDs. Procurou-se verificar se nos últimos dois anos os entrevistados haviam contratado algum tipo streaming e constatou-se que 31,90\% assinou streaming de vídeo, 16,67\% de música, 29,52\% de vídeo e música e apenas $21,90 \%$ nunca assinou nenhum desses serviços. Isso demonstra que $78,10 \%$ dos entrevistados já consumiu algum tipo de serviço digital através de assinatura.

O último grupo de perguntas para entender os hábitos de consumo desse nicho focou em viagens, refeições em restaurantes, volume de gastos em $\mathrm{R}$ \$ com roupas e acessórios, troca de tecnologia e acesso a cultura.

Nos últimos seis meses $54,76 \%$ dos entrevistados foram ao teatro, $81,43 \%$ ao cinema, $54,29 \%$ a shows de música, 30,95\% assistiu pelo menos um espetáculo de dança, 64,29\% visitou feiras e exposições culturais e somente $4,76 \%$ não frequentou nenhum dos locais. Observou-se, que das opções cultuais, o cinema é o mais consumido pelo público pesquisado.

Além disso, 21,90\% come pelo menos 1 vez durante a semana em restaurantes, $19,05 \%$ até 2 vezes, 19,05\% diz comer até 3 vezes, 9,52\% até 4 vezes, 17,62\% mais de 5 vezes e $12,86 \%$ responderam que não costumam comer em restaurantes.

Outro dado interessante é a quantidade de vezes que eles viajaram nos últimos dois anos. Da amostra, 40,95\% dos entrevistados viajou mais de 5 vezes, 14,76\% diz ter viajado 4 vezes, 15,24\% fez pelo menos 3 viagens, 14,76\% viajou 2 vezes, 7,62\% somente 1 vez, os outros 6,67\% não viajou nenhuma vez durante os dois últimos anos. Quanto aos gastos médios durante as viagens foram: $25,24 \%$ gasta até $\mathrm{R} \$ 1.000,21,43 \%$ entre $\mathrm{R} \$ 1.001$ e $\mathrm{R} \$$ 
2.000, 16,67\% entre $\mathrm{R} \$ 2.001$ e $\mathrm{R} \$ 3.000,24,29 \%$ mais de $\mathrm{R} \$ 3.001$, e para $12,38 \%$ dos entrevistados a pergunta não se aplicava pois não tinham viajado nesse intervalo de tempo ou não lembravam o valor médio gasto.

Já os gastos médios com vestuário e acessórios por ano foram: 20,00\% gasta até R\$ $500,27,14 \%$ entre $\mathrm{R} \$ 501$ e $\mathrm{R} \$ 1.000,23,33 \%$ entre $\mathrm{R} \$ 1.001$ e $\mathrm{R} \$ 2.000$ e 29,52\% gasta mais de $\mathrm{R} \$ 2.001$ por ano.

Na pergunta sobre troca de celular constatou-se que apenas 13,81\% troca de aparelho sempre que sai um lançamento e $86,19 \%$ somente troca quando estraga o celular que possuem. Já com relação ao intervalo médio que se troca de celular: 1,43\% diz trocar a cada seis meses, $16,67 \%$ a cada ano, $28,57 \%$ a cada dois anos e $53,33 \%$ troca somente quando o que tem deixa de ser funcional.

Sobre as formas de pagamentos que normalmente utilizam: 52,38\% paga em dinheiro. Na modalidade de pagamento via cartão temos que: 72,38\% usa débito, 57,62\% crédito à vista e $55,71 \%$ crédito parcelado. Ainda temos uma parcela dos entrevistados que usa cheque representando $1,90 \%$ da amostra e 35,24\% usa boleto bancário. Já os métodos de pagamento online tiveram uma representatividade de $22,86 \%$. Nessa pergunta era possível escolher mais de uma opção e nenhuma delas obteve $100 \%$.

Quando questionados sobre a forma de pagamento que mais utilizam, o método via cheque não teve porcentagem nas respostas, cartão de débito e crédito à vista se destacaram com $40,95 \%$ e $24,76 \%$ respectivamente, seguidos por crédito parcelado com 16,19\%, dinheiro com $11,43 \%$, seguidos de boleto bancário com $5,24 \%$ e apenas $0,95 \%$ utiliza mais os métodos de pagamentos online. Observou-se que a forma de pagamento com dinheiro esta caindo em desuso. Esses dados ajudam a entender quais seriam formas mais adequadas de pagamentos para oferecer para esse público.

Para entender um pouco sobre planejamento futuro e estabilidade financeira, foi perguntado aos entrevistados se possuíam casa ou apartamento próprio e 42,38 respondeu que tem um imóvel próprio, 32,38\% não possui nenhum, e 25,24\% não tem, mas planeja comprar nos próximos 5 anos. Com relação a carro próprio: 41,90\% tem, 44,29\% não possui, e 13,81\% atualmente não tem, mas planeja comprar nos próximos 5 anos. Com esses dados é possível verificar que existe uma parte dos entrevistados que já tem uma estabilidade e compraram bens duráveis e outra parte que tem planos de adquirir algum desses bens nos próximos 5 
anos. Com essas informações é possível, por exemplo, direcionar campanhas de venda de imóveis para esse nicho já que existe o desejo e alguns planejam adquirir bens duráveis.

Com o excesso de informação disponível e a diversidade de produtos semelhantes no mercado, os consumidores procuram as fontes mais confiáveis para poder obter dados relevantes antes de efetuarem uma compra. Já se sabe que três fatores básicos influenciam o consumidor antes da compra: primeiro temos a comunicação de marketing em diferentes mídias, segundo as opiniões de familiares/amigos e terceiro o conhecimento prévio e as experiências próprias do consumidor (Kotler et al., 2017), por isso nesse eixo foram aplicadas 17 perguntas para poder identificar de que forma as pessoas desse nicho buscam informações, como eles influenciam outros compradores e se a sexualidade interfere na escolha dos produtos ou serviços.

Antes de comprar um produto que nunca foi consumido, 51,43\% respondeu que busca informação primeiramente no Google, 20,95\% em lojas online, 11,43\% pergunta para amigos, $8,57 \%$ utiliza as redes sociais como base de informação e 7,62\% vai até uma loja física para conhecer o produto. Quando se tratam de críticas negativas 40,95\% diz que os comentários em redes sociais e sites como Reclame Aqui são os dados que mais influenciam antes de efetuar uma compra, 29,05\% acha que comentários de amigos e conhecidos é mais relevante, $25,24 \%$ considera as informações encontradas em sites e blogs especializados, e apenas $4,76 \%$ acredita nas informações repassadas por vendedores ou no site da loja quando o foco são os aspectos negativos de um produto/serviço.

Com relação aos aspectos positivos e elogios à um produto/serviço os amigos e conhecidos se tornam a fonte mais relevante com $38,10 \%$ da amostra dizendo que confia na opinião dos amigos, já 31,43\% dos entrevistados acham que as informações encontradas em sites e blogs especializados são a base mais confiável antes de uma compra, 27,14\% considera os comentários em redes sociais e sites como Reclame Aqui os mais relevante e apenas 3,33\% se baseia em informações repassadas por vendedores ou no site da loja que vende o produto.

A pesquisa procurou também identificar em termos gerais qual é a opinião menos importante antes de uma compra e revelou que para o público pesquisado a opinião dos vendedores ou site das lojas é a menos confiável com 61,90\% de rejeição, as informações disponibilizadas em sites e blogs especializados obteve 11,90\%, os comentários em redes sociais e sites como Reclame Aqui ficaram com 13,81\% e comentários de amigos e 
conhecidos $12,38 \%$. Pelo perfil dos entrevistados e as respostas obtidas observa-se que há um tendência a não se confiar muitos nos vendedores ou sites especializados optando por buscar apoio muito mais nas redes e ciclos mais próximos de amigos.

Buscou-se entender também qual é o grau de influencia e de referência que os gays tem nos ciclos mais próximos. Para isso foi perguntado se os amigos e/ou familiares costumam pedir a opinião deles sobre produtos/serviços antes de comprarem alguma coisa. $76,19 \%$ dos entrevistados responderam que são consultados por familiares ou amigos, e apenas $23,81 \%$ não são consultados por pessoas próximas antes de uma compra. Os assuntos nos quais eles normalmente são consultados são: 63,81\% são perguntas sobre tecnologia e eletrônicos, 38,57\% em assuntos de turismo e lazer, 37,14\% coisas relacionadas a moda e acessórios, 30,95\% são consultados em assuntos de alimentos e bebidas, 24,29\% sobre educação, $13,33 \%$ dos entrevistados disseram que não são consultados em nenhum dos assuntos e 5,24\% em outros assuntos conforme representado na Figura 2.

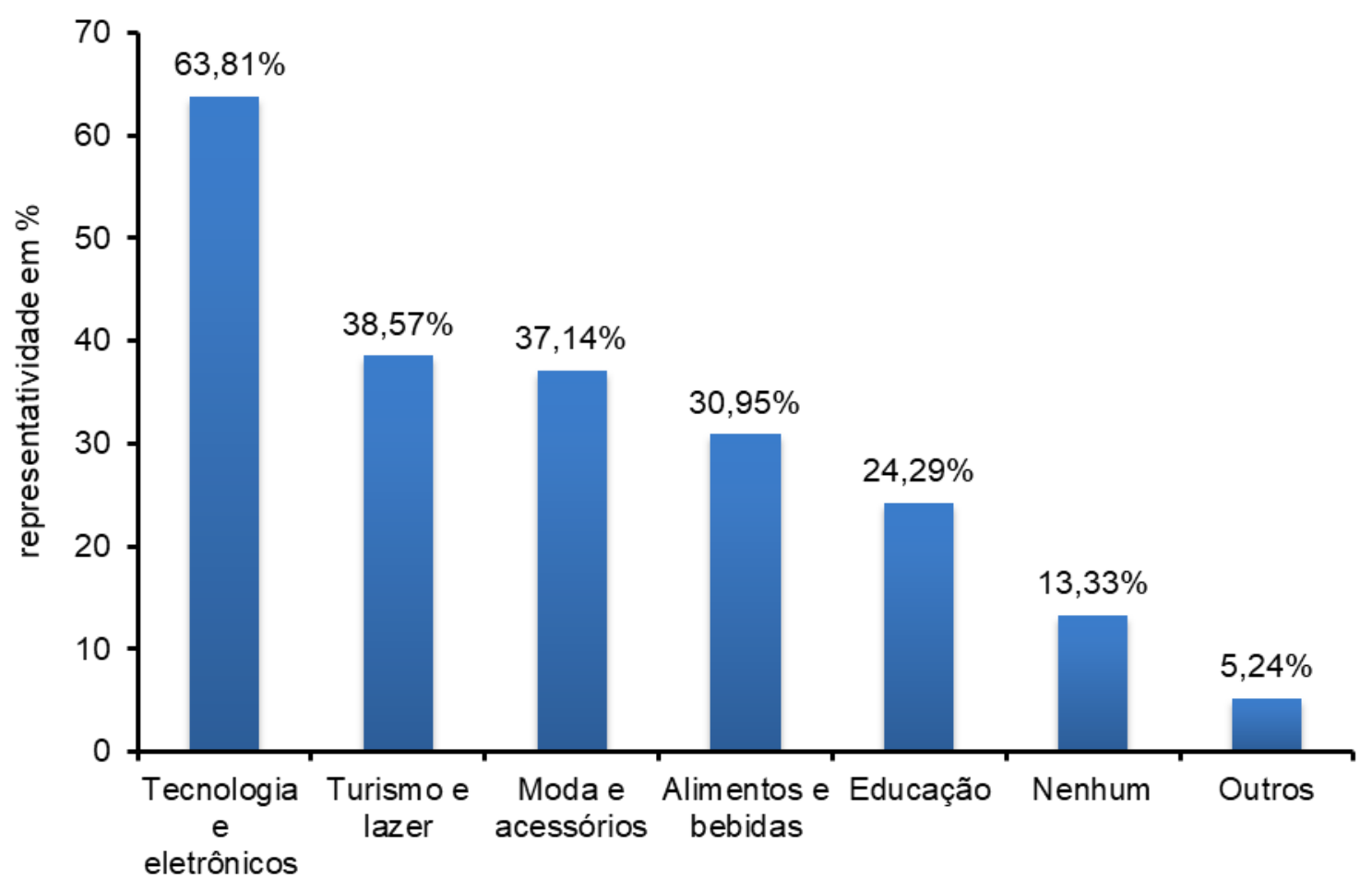

Figura 2. Assuntos nos quais os entrevistados normalmente são consultados

Fonte: Resultados originais da pesquisa 
Para saber se eles são clientes que divulgam um produto/marca quando gostam foi perguntado quando foi a última vez que recomendaram algum produto ou serviço a um conhecido. 16,67\% fizeram alguma recomendação nas últimas 24 horas, 33,81\% durante a última semana, $28,57 \%$ no último mês, $10,48 \%$ em algum período nos últimos seis meses, 2,86\% há pelo menos um ano, 0,48\% há mais de um ano e 7,14\% não lembrava, mas havia feito recomendações. Todos os entrevistados haviam recomendado alguma coisa para alguém. A opção 'nunca recomendei' não obteve nenhuma resposta.

Com relação a espontaneidade das recomendações foi questionado se ao gostarem de um produto, serviço ou estabelecimento costumam comentar com conhecidos de forma espontânea. Para essa pergunta utilizou-se uma escala de 1 a 10, em que 1 significava nunca e 10 significava sempre. Nos extremos temos apenas $1,90 \%$ que nunca comentam sobre os produtos que gostaram se contrapondo aos $34,76 \%$ que sempre comentam de forma espontânea com amigos e familiares conforme Figura 3.

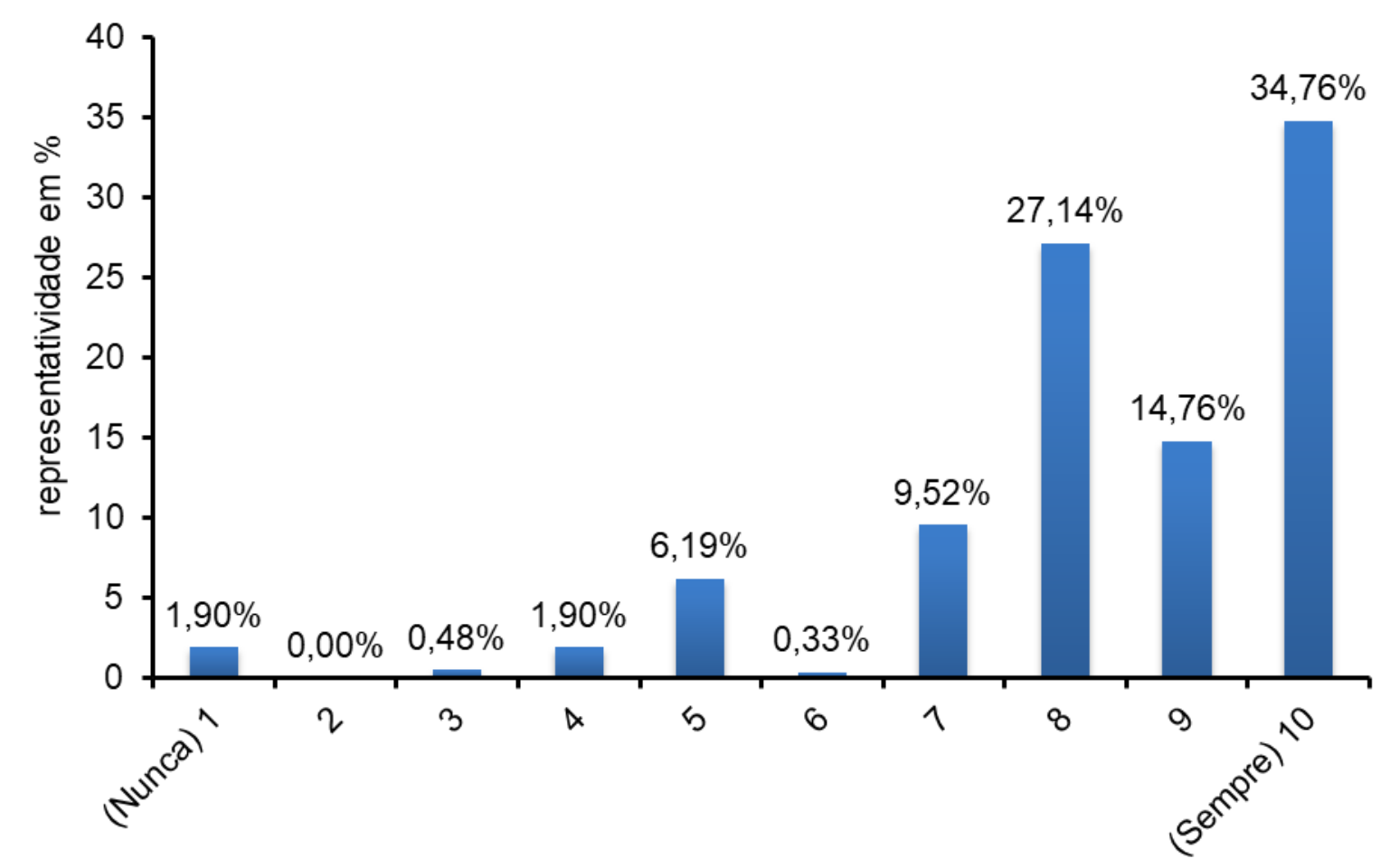

Figura 3. Comentarios expontâneos quando gostam de algum produto

Fonte: Resultados originais da pesquisa

Para facilitar a analise as respostas foram agrupadas em dois blocos: de 1 a 5 com menor probabilidade de comentarem a respeito dos produtos e um segundo grupo de 6 a 10 
como sendo os mais propensos a comentar espontaneamente. Com base nessa separação obteve-se $10,48 \%$ das respostas no primeiro grupo e no grupo dos mais espontâneos a comentarem chegamos a $89,52 \%$, o que sugere que os participantes desse nicho possuem um comportamento do tipo que pode ser enquadrado no "share of mind" (Yanaze, 2011), já que quando esse compartilhamento espontâneo acontece podemos dizer que o consumidor está em um processo de relacionamento com a marca (McEwen, 2005) e ao mesmo tempo desenvolvendo o processo de evangelização da marca, no qual pode converter novos consumidores (Atkin, 2007).

Por ser um grupo de consumidores que infelizmente ainda sofre preconceito em diversas áreas da sociedade, procurou-se entender de qual forma a sexualidade interfere ou estimula o consumo de produtos/serviços. Para isso usamos cinco perguntas sendo a primeira para identificar se eles costumam consumir produtos de uma empresa que se declare "gay friendly”, termo que segundo Péret (2011) se refere tanto a instituições ou indivíduos que demonstram respeito à diversidade sexual, tendo posturas inclusivas. 34,29\% responderam que consomem produtos de empresas declaradas "gay friendly" e a maioria da amostra totalizando $65,71 \%$ disse que não. Ao mesmo tempo que 47,14\% já participou de algum boicote a marcas que demonstram preconceito contra gays e 52,86\% nunca participaram.

Os motivos pelos quais eles podem deixar de ser clientes de uma empresa são: para $50,95 \%$ o mau atendimento é o fator que motiva a decisão, $23,81 \%$ disse que a qualidade ruim dos produtos, $18,10 \%$ responderam que quando a empresa tem atitudes preconceituosas ou homofóbicas, para 2,38\% a burocracia no processo de compra é o motivador para deixar de ser cliente e a para $1,43 \%$ falta de responsabilidade social obteve. 3,33\% dos entrevistados não soube responder por qual motivo eles cortariam a relação com uma empresa.

Na hora de escolher um destino de viagem o fator que mais importa na tomada de decisão para 11,90\% dos entrevistados é o local ser seguro para a população gay, 6,19\% preferem locais que tenham uma vida noturna agitada para o segmento, 20,48\% é mais sensível ao preço e define o local de acordo com o valor, ao passo que 61,43\% escolhe o local apenas porque gostaria de conhecer, independente da receptividade do local com o público LGBTI.

Procurou-se identificar se as produções culturais como o cinema e as novelas conseguem retratar um universo no qual esse espectador se projeta e reconhece situações que correspondem a interesses intimamente ligados a questões pessoais (Morin, 2002). Então para 
entender se personagens gays ajudam a conectar produtos culturais com esse nicho, foi perguntado se ao saber que um programa de TV, novela ou filme tem um personagem LGBTI eles assistiriam, para 6,19\% dos entrevistados eles nunca assistem, 16,19\% responderam que sempre, e 77,62\% dependendo do tema. O que da sustentabilidade para a ideia de que é necessário que haja identificação desse nicho com os temas em produções culturais.

Sobre o local que os entrevistados consomem produtos e serviços, a mostra indica que esse é um nicho que se locomove pela cidade já que $78,10 \%$ disse que adquire os produtos/serviços em qualquer lugar da cidade, e apenas 21,90\% somente em estabelecimentos próximos de casa e trabalho.

As três últimas perguntas buscaram entender de que forma eles avaliam a comunicação e publicidade direcionada ao segmento.

Quando questionados se nos últimos 6 meses tinham visto alguma campanha publicitária direcionada para o público LGBTI, 78,10\% disse que sim e 21,90\% não. A forma com que eles qualificam as campanhas também foi um dos pontos levantados pelo questionário e 46,67\% responderam que poucas empresas retratam os gays de forma normal e sem os estereótipos, 16,67\% acha que não há campanhas suficiente para serem avaliadas, 3,33\% classificou as campanhas como negativas porque sempre usam estereótipos e clichês, $8,10 \%$ não tinha opinião sobre esse tema e apenas $25,24 \%$ considerou a representação do segmento nas campanhas positiva.

A pesquisa buscou entender também qual é linguagem adequada para ser usada nas campanhas de comunicação, de acordo com a análise dos membros desse nicho. Foi questionado aos participantes de que forma eles achavam que as equipes de marketing deveriam abordar a diversidade em suas campanhas. As respostas foram todas dissertativas e de livre número de caracteres. Nas respostas apareceram algumas palavras que se repetiram diversas vezes dentre as 210 respostas conforme ilustrado na Tabela 3.

Tabela 3. Incidência de palavras

\begin{tabular}{ll}
\hline Termo & Número de repetições \\
\hline Naturalmente & 75 \\
Respeito & 49 \\
Normalmente & 37
\end{tabular}


Sem estereótipos

De forma inclusiva

Com empatia

De forma positiva

Fonte: Resultados originais da pesquisa

Para os entrevistados as campanhas deveriam focar de forma normal e não nos clichês. Entre os respondentes não houve nenhuma voz exigindo a inclusão ou para serem tratados diferentes, mas sim de forma natural e inclusiva. Já 13 dos participantes disseram ser contra o uso de bandeiras em campanhas publicitárias. Algumas das respostas foram: 'Não acho legal quando ativismo vira alvo de campanha de marketing'; 'Acho errado o uso da pauta de diversidade como foco principal numa campanha'; 'De forma regular já que não acho obrigatório', e 'Não vejo motivo para diferenciar'. Outro fator que se destacou foi a sensibilidade dos entrevistados com relação as empresas que querem apenas atrair atenção. Isso foi possível perceber em trechos de respostas como: 'Infelizmente vemos hoje usarem a imagem do gay como forma de ganhar público', e 'Deveriam tratar de forma natural sem parecer que estão tentando causar impacto'. Isso sugere que os membros desse nicho estão observando como as empresas se comportam com relação ao segmento. Por isso as marcas devem se mostrar autênticas e honestas ao se relacionarem com os clientes para criarem laços duradouros (Kotler et al., 2017).

\section{Conclusão}

Buscou-se com esse trabalho identificar o perfil do consumidor gay masculino e conhecer a percepção que eles têm sobre as campanhas de marketing direcionadas ao segmento LGBTI. Frente a um mercado com uma gama de ofertas de produtos semelhantes, focar em segmentação de clientes é um dos melhores caminhos para o desenvolvimento das empresas.

Os respondentes da pesquisa se mostraram observadores e percebem quando as marcam não estão sendo verdadeiras em suas campanhas. Uma vez encantado pela marca ou produto esse nicho tem um comportamento espontâneo e compartilha com pessoas próximas os pontos positivos, podendo assim se tornarem advogados da marca, e com isso atrair novos 
consumidores. Porém é necessário trabalhar de forma inclusiva e natural para obter a confiança deles. É importante ter comprometimento verdadeiro com relação a esse segmento além de buscar satisfazer os desejos desses consumidores.

Observou-se que os participantes da entrevista não querem ser tratados diferentes dos outros consumidores, mas sim de forma igualitária e natural, sem virarem bandeira de empresas que querem causar um "buzz" no mercado. Além disso, declarar-se como sendo uma empresa "gay friendly" não fará com que esse nicho aceite a marca como parte da vida deles. Isso indica para as empresas que as ações de marketing precisam ser humanizadas e possuírem uma identidade verdadeira, ou seja, no DNA da empresa precisa ter verdadeiramente a vontade de atender esse nicho e não apenas estar focado em vender mais.

O consumidor gay está conectado nas redes sociais e é usuário frequente nas principais delas. Assumir a sexualidade não se mostrou um tabu entre os entrevistados. Eles possuem um poder de compra em termos gerais muito positivo, além de serem influenciadores dos ciclos mais próximos, pois são consultados com frequência por amigos e familiares que querem saber sobre algum tipo de produto ou serviço. Existe uma parte dos entrevistados que se enquadram na definição de "DINKs - Double Income no Kids", que tem o desejo de adotar uma criança e constituir uma família, isso indicou que existe um micronicho dentro do nicho de consumidores gays com união estável.

O investimento no marketing direcionado à esse consumidor pode atrair bons resultados financeiros para o caixa das empresas, uma vez que o segmento continua sendo mal explorado pelas marcas. Quem entender o contexto histórico pelo qual o segmento vem passando, os desejos, as percepções e observações que eles tem sobre o mercado e as marcas, sairá na frente e poderá conquistá-los como consumidores fiéis, como já fizeram diversas empresas em mercados consolidados como dos Estados Unidos e da Suécia.

\section{Referências}

Atkin, D. (2007). O Culto às Marcas - Quando os clientes se tornam verdadeiros adeptos. Editora Cultrix, São Paulo, SP, Brasil.

Combs, W.; Witeck R. 2006. Business Inside Out: Capturing Million of Brand Loyal Gay Consumers. Editora Kaplan Publising, Chicago, IL, United States of America. 
Gluckman, A.; Reed, B. 1997. Homo Economics: capitalism, community and lesbian and gay life. Editora Routledge, New York, NY, United States of America.

Green, J.N.; Polito, R. 2006. Frescos Trópicos: Fontes Sobre a Homossexualidade Masculina no Brasil (1870-1980). Editora Olumpio, Rio de Janeiro, RJ, Brasil.

Junger, A. P., Marin, A. C., Facó, J. F. B., \& Araújo, L. M. (2017). The perceived value on online videogames and the construction of its consumer. Research, Society and Development, $6(1), 64-75$.

Kotler, P.; Kartajaya, H.; Setiawan, I. 2010. Marketing 3.0: As formas que estão definindo o novo marketing centrado no ser humano. 3ed. Elsevier, Rio de Janeiro, RJ, Brasil.

Kotler, P.; Kartajaya, H.; Setiawan, I. 2017. Marketing 4.0 - do tradicional ao digital. Editora Sextante, Rio de Janeiro, RJ, Brasil.

Kotler, P.; Keller, K.L. 2012. Administração de Marketing. 14ed. Editora Pearson, São Paulo, SP, Brasil.

Kotler, P.; Kotler, M. 2013. Marketing de Crescimento - 8 estratégias para conquistar mercados. Editora Elsevier, Rio de Janeiro, RJ, Brasil.

McEWEN, W.J. 2005. Married to the Brand - why consumers Bond with some brands for life. Editora Gallup Press, New York, NY, United States of America.

Morin, E. 2002. Cultura de Massa no Século XX: O Espírito do Tempo - Neurose. 9ed. Editora Forense Universitária, Rio de Janeiro, RJ, Brasil.

Out Now Consulting. 2017. Brazil 2017 Report - Out Now Global LGBT2030 Study. Disponível em: <https://www.outnowconsulting.com>. Acesso em: 21 jul. 2018.

Péret, F. 2011. Imprensa Gay no Brasil. Editora Publifolha, São Paulo, SP, Brasil. 
Reinaudo, F.; Bacellar, L. 2008. O Mercado GLS. Editora Ideia \& Ação, São Paulo, SP, Brasil.

Ribeiro, I.R. 2010. A TV no Armário: A Identidade gay nos programas e telejornais brasileiros. Editora: Edições GLS, São Paulo, SP, Brasil.

Rosenwald, P.J. 2005. Accountable Marketing - Otimizando resultados dos investimentos em Marketing. Editora Thomson, São Paulo, SP, Brasil.

Roth, A. E. 2016. Who Gets What and Why. Editora Mariner Books, New Yourk, NY, United States of America.

São Paulo Turismo [SPTuris]. 2010. Relatórios Mega Eventos 2010. Disponível em: http://www.observatoriodoturismo.com.br. Acesso em: 19 jul. 2018.

Sender, K. 2004. Business, Not Politcs - the making of gay market. Editora Colombia University Press. New York, NY, United States of America.

Sordi, J.O. 2017. Desenvolvimento de Projeto de Pesquisa. Editora Saraiva, São Paulo, SP, Brasil.

Souza, E.R. 2007. A Gestualidade na Construção do Estereótipo do Personagem Homossexual no Cinema. Dissertação (Mestrado em Comunicação) - Programa de PósGraduação em Comunicação. Universidade Paulista - UNIP. São Paulo, SP, Brasil. Disponível em: <http://www.dominiopublico.gov.br/pesquisa/DetalheObraForm.do?select_ action=\&co_obra=85543> . Acesso em: 01 jun. 2018.

Venturi, G.; Bokany, V. 2011. Diversidade Sexual e Homofobia no Brasil. Editora Fundação Perseu Abramo, São Paulo, SP, Brasil.

Yanaze, M.H. 2011. Gestão de Marketing e Comunicação: - avanços e aplicações. 2ed. Editora Saraiva, São Paulo, SP, Brasil. 


\section{Res., Soc. Dev. 2019; 8(5):e3385970}

ISSN 2525-3409 | DOI: http://dx.doi.org/10.33448/rsd-v8i5.970

Zanatta, E.M. 1997. Documento e Identidade: Homossexual no Brasil na década de 80.

Cadernos AEL - Arquivo Edgard Leuenroth, Centro de Pesquisa e Documentação Social 5/6:

193-220. Disponível em: <https://www.ifch.unicamp.br/ojs/index.php/ael/issue/view/142>. Acesso em: 02 jun. 2018.

Porcentagem de contribuição de cada autor no manuscrito

Sidney Pereira da Silva - 25\%

Caio Flávio Stettiner - 25\%

Roberto Padilha Moia - 25\%

Alex Paubel Junger - 25\% 